\title{
Improvement of the copy-book of nutrient medium for input of meristems of grapes in the culture of in vitro
}

\author{
Anton Rebrov, ${ }^{1, *}$ \\ ${ }^{1}$ All-Russian Research Ya.I.Potapenko Institute of Viticulturel and Winemaking - Branch of Federal \\ State Budget Scientific Institution "Federal Rostov Agricultural Research Centre", 346421, \\ Baklanovsky av., 166, Novocherkassk, Russia,
}

\begin{abstract}
Results of researches on development of substrate for input of meristems of grapes are provided to the culture of in vitro for the purpose of increase in their regenerative ability at improvement from chronic diseases. In the advanced environment in comparison with analogs the general content of macrosalts was reduced and their ratio taking into account consumption and features of their absorption from nutrient solution is optimized by grape plant. During tests of new substrate its efficiency for grapes grades from various environmental-geographical groups was established. Higher and stable percent of survival and regeneration of extremely small meristems, against the background of various modifications of copy-book of traditionally applied substrate of Murasige and Skuga is established.
\end{abstract}

\section{Introduction}

Input in the culture of in vitro, very difficult, labor-consuming and responsible operation. Its main complexity is that improvement from viruses and other chronic diseases most successfully happens when using extremely small size of the explant as which, as the most genetically stable object, most often use apical meristem. Further from the isolated apical meristem of the extreme small size (for grapes it is the sizes of $\approx 100$ microns), it is necessary to regenerate the whole plant. For this purpose researchers developed bioprocessing methods which basis is creation of special sterile conditions (in vitro), for cultivation of the isolated explant on artificial substrate. To contain in such environment all main nutrients necessary for plants macro and microelements, carbon source (most often sucrose), in it assign some vitamins and amino acids, however special part to phytohormones. Exogenous introduction of phytohormones is one of major factors the directing processes of morphogenesis of in vitro.

At the beginning of input of meristems in the culture of in vitro, apply phytohormones from group of tsitokinin (for grape plant it is most often 6-BAP) to their development and removal of apical domination. Further if necessary, for increase in length of interstices at escapes, apply gibberellins, and to their rooting auxins. Considering special importance of

*Corresponding author: rebrow-anton@yandex.ru 
phytohormones, at improvement of bioprocessing methods, most of researchers pay the greatest attention to question of hormonal regulation. For different types of the plants and grades having specificity to cultivation in the conditions of in vitro optimum concentration and types of hormones and also their combination and proportions are selected. The seldom upgradeablest part of substrate is its mineral composition (macro and microelements are more rare). It is connected, first of all with complexity of similar experiments as at change of concentration of macrosalts in substrate it is necessary to consider features of their absorption by plants, antagonism and their synergism in various ratios and concentration. At the same time most often most of researchers at microcloning of grapes use as basic mineral basis copy-book of the Murasige environment and Skuga (MS) [1-10]. Less often works in which authors use insignificant modifications of mineral basis of this environment [11] meet, or study against the background of MS efficiency of other standard environments [12-17]. In spite of the fact that researchers give preference in the majority of scientific works on microclonal reproduction of plants to the MS environment, this environment possesses number of the shortcomings caused by the fact that it was developed for cultivation of kallusny cells of tobacco and its main shortcoming at regeneration of meristems is high concentration of salts of $4.7 \mathrm{~g} / \mathrm{l}$. Owing to what, for absorption of the elements dissolved in it the plant needs to overcome osmotic pressure about $2.5 \mathrm{~atm}$., in case of input in culture, it not plant, but extremely small site of apical meristem. Except this shortcoming it is necessary to point to unbalanced ratio of macrocells taking into account their requirement by grapes plants. In mineral basis of substrate of MS big imbalance towards $\mathrm{N}, \mathrm{K}$ and $\mathrm{Cl}$ concerning other elements, at the same time a lot of nitrogen is provided by ammonium form (NH4), plants prefer nitrate (NO3), in this regard at absorption of $\mathrm{NO} 3$ in the environment there will be $\mathrm{NH} 4$, and at absorption of $\mathrm{Ca}$ from $\mathrm{CaCl} 2$, there will be a lot of not acquired $\mathrm{Cl}$, all this will promote substrate acidulation. Acidulation is lower than $5.0(\mathrm{pH})$, in turn negatively affects absorption of phosphorus and magnesium and also does number of microelements phytotoxic. Possibly, it is one of factors of the frequent changes causing need, at stage of proliferation, vegetable conglomerates when using the MS environment.

All aforesaid, defined the purpose of our researches to develop and test compounding of substrate in which there would be no shortcomings MS inherent in substrate that would promote improvement of regeneration of meristems of grapes of extremely small sizes.

\section{Materials and methods}

Researches were conducted in the conditions of laboratory of biotechnology VNIIVIV of Ya.I. Potapenko - FRANZ FGBNU branch in 2014-2017, by the standard techniques in biotechnology. Objects of researches of grade of grapes from different environmentalgeographical groups and difficult interspecies hybrids. Input of meristems was carried out in phase of active growth of plants, June-July. Meristems isolated from upper part of the green escapes which are previously cut on one-eye shanks with remote leaves and short moustaches. The prepared plant material was previously sterilized, $70 \%$ water solution of ethanol and $20 \%$ sodium hypochlorite. Meristems isolated in the laminar-flow cabinet under the MBS-9 binocular microscope with the lighter. For the purpose of chronic diseases relief of plants, isolated meristems no more than $0.1 \mathrm{~mm}$ in size. After disembarkation of meristems to substrates supported the following culture conditions: temperature is $23 \div 24$ of ${ }^{\circ} \mathrm{C}$, illumination is $2300 \div 2500$ of $1 \mathrm{x}$, the photoperiod of $16 \backslash 8 \mathrm{~h}$. On all options of experience landed 50 meristems. Accounting carried out in month after disembarkation. Statistical analysis was carried out by method of confidence intervals, by means of "package of the analysis" of the Excel MS Office 2010 program of the confidential probability of $95 \%$. 
Confidence intervals for the indicators expressed in \% are calculated by E.B. Wilson's technique (1927).

When developing substrate for input and regeneration of meristems in the culture of in vitro we considered data on ratio of nutrients in green escapes and leaves of grapes generalized on the basis of the analysis of numerous researches by K.D. Stoyev (1981) and also the rules and criteria recommended in hydroponics by drawing up substrates, which are also generalized by Garlic VA. and E.V. Bazyrina (1960). Substrates differed only in composition of macrosalts, all other components: microsalts, sucrose, vitamins, hormones, agar-agar, added to all options in identical quantity. Comparative data on ratio and concentration of macrocells in substrates are provided in tables 1 and 2.

Table 1. Ratio of macrocells (concerning nitrogen), in the tested substrates

\begin{tabular}{|l|l|l|l|l|l|l|l|l|l|}
\hline \multirow{2}{*}{ № } & \multirow{2}{*}{$\begin{array}{l}\text { Experience } \\
\text { options }\end{array}$} & \multicolumn{8}{|l|}{ Ratio of macrocells in substrates to nitrogen } \\
\cline { 3 - 10 } & N & P & K & Mg & S & Cl & Na & Ca \\
\hline 1. & MS 1/1 & 1,00 & 0,05 & 0,93 & 0,04 & 0,06 & 0,33 & 0,005 & 0,19 \\
\hline 2. & MS 2/3 & 1,00 & 0,05 & 0,93 & 0,04 & 0,06 & 0,33 & 0,008 & 0,19 \\
\hline 3. & MS 1/2 & 1,00 & 0,05 & 0,93 & 0,04 & 0,06 & 0,33 & 0,010 & 0,19 \\
\hline 4. & AR & 1,00 & 0,13 & 1,22 & 0,12 & 0,15 & 0,05 & 0,060 & 0,34 \\
\hline min* & 1,00 & 0,15 & 0,35 & 0,12 & 0,10 & 0,01 & 0,010 & 0,60 \\
\hline max* & 1,00 & 0,35 & 1,20 & 0,25 & 0,20 & 0,15 & 0,150 & 1,40 \\
\hline
\end{tabular}

* Range of ratios of macrocells in draws and leaves of grapes

Table 2. The maintenance of macrocells in the tested substrates and limits of their optimum min and max values

\begin{tabular}{|c|c|c|c|c|c|c|c|c|c|}
\hline \multirow[t]{2}{*}{ № } & \multirow{2}{*}{$\begin{array}{l}\text { Experience } \\
\text { options }\end{array}$} & \multicolumn{8}{|c|}{$\begin{array}{l}\text { The maintenance of macrocells in substrate on of century, } \\
\mathrm{mg} / \mathrm{l}\end{array}$} \\
\hline & & $\mathbf{N}$ & $\mathbf{P}$ & K & Mg & $\mathbf{S}$ & Cl & $\mathbf{N a}$ & $\mathrm{Ca}$ \\
\hline 1. & MS 1/1 & 841,6 & 38,8 & 782,2 & 36,6 & 48,1 & 281,2 & 4,9 & 158,8 \\
\hline 2. & MS 2/3 & 631,2 & 29,1 & 586,6 & 27,5 & 36,1 & 210,9 & 4,9 & 119,1 \\
\hline 3. & MS $1 / 2$ & 420,8 & 19,4 & 391,1 & 18,3 & 24,1 & 140,6 & 4,9 & 79,4 \\
\hline 4. & AR & 297,1 & 37,2 & 361,8 & 34,7 & 45,5 & 16,0 & 19,2 & 101,0 \\
\hline \multicolumn{2}{|c|}{$\min *$} & 56,0 & 12,0 & 59,0 & 12,0 & 20,0 & - & - & 12,0 \\
\hline \multicolumn{2}{|c|}{$\max ^{*}$} & 250,0 & 150,0 & 500,0 & 84,0 & 331,0 & - & - & 217,0 \\
\hline
\end{tabular}

* The recommended range of concentration of macrocells on of century for cultivation of plants on hydroponic solutions

Apparently from the provided tables, in various modifications of substrate of MS only concentration of macrocells change, their ratio remains invariable. At the same time it is necessary to point to high content, in the MS substrate: nitrogen, potassium and chlorine concerning other macrocells, these disproportions in the ratio, differ from the recommended levels according to the recommendations on food of plants developed for hydroponics and are not overcome by multiple change of concentration in $\mathrm{MC}^{3} / 4$ and $\mathrm{MC}^{1} / 2$. In the developed environment (ARE) these shortcomings tried to consider and also to reduce the general concentration of macrosalts to $2.2 \mathrm{~g} / \mathrm{l}$.

The research provided by us consisted of 2 experiments (stages). In the first against the background of 3 modifications of copy-book of substrate of MS, tested the substrate developed by us. Modifications of MS represented multiple concentration macro - structure of 100,75 and $50 \%$, these are 4,7,3,5 and $2.4 \mathrm{~g} / \mathrm{l}$ respectively, for studying influence on processes of regeneration of meristems of concentration of salts in nutrient solution. At the second stage, for more detailed study of efficiency of the developed substrate copy-book we compared it to the best modification $\mathrm{MC}^{3} / 4$. In total at the second investigation phase 
within three years more than 20 grades of grapes from different environmentalgeographical groups, were used for identification of efficiency of substrate ARE in section of high-quality specificity to in vitro conditions. In this work because of impossibility to provide all results, only grades with the most typical reaction are shown.

\section{Discussion of results}

The research on influence of concentration and ratio of macrocells in substrates carried out in several steps. In the first experience compared three multiple modifications of MS and the developed ARE environment. Results of the first experiment are presented on figure 1 and table 3 .

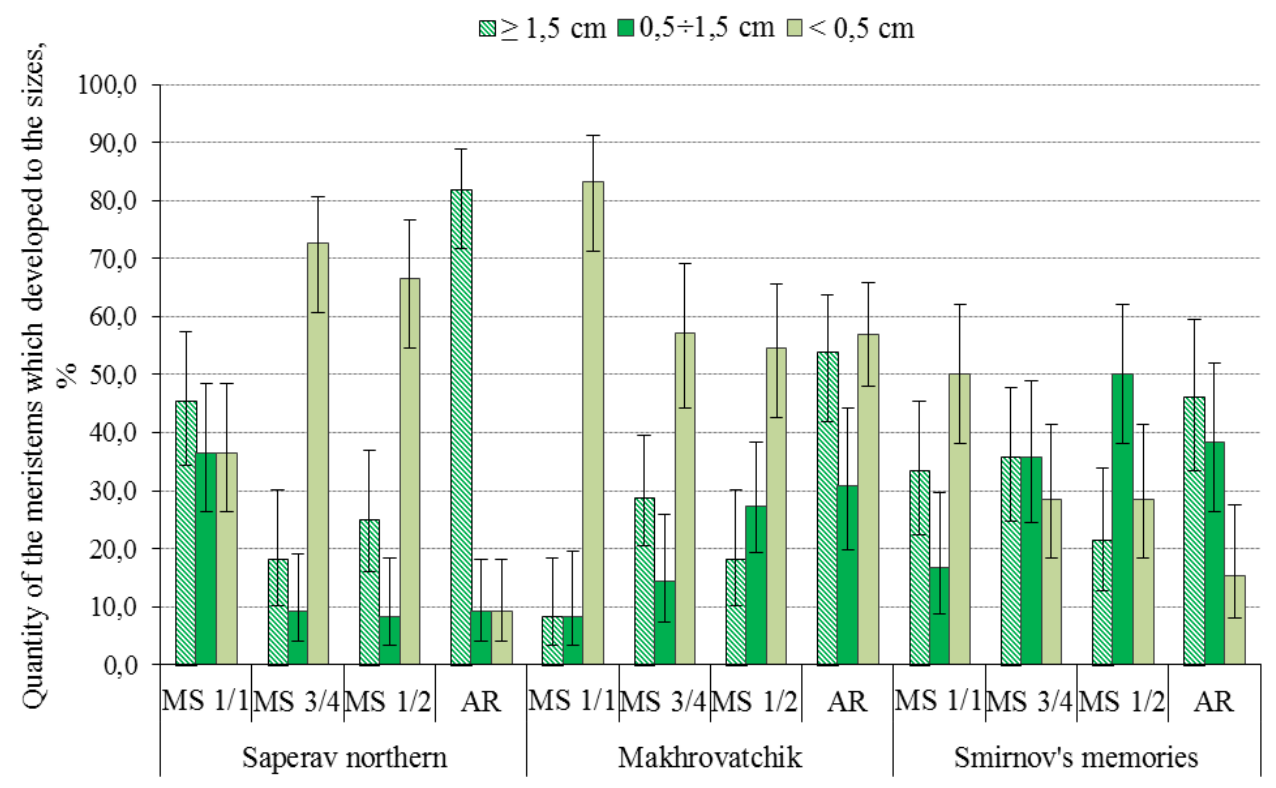

Fig. 1. Regeneration of meristems on substrates with various compounding of macrosalts

Grades - difficult interspecies hybrids from different environmental-geographical groups were involved in research. For the majority of grades the noticeable positive trend was noted in the second option, in modification of the MS environment with reduced concentration of macrosalts from $4.7 \mathrm{~g} / 1$ to $3.5 \mathrm{~g} / 1$ of the environment. When using such modification $\left(\mathrm{MC}^{3} / 4\right)$, at the majority of grades observed noticeable increase in percent of well developed meristems $(\geq 1.5 \mathrm{~cm})$ from which in $2-4$ weeks with high probability it is possible to receive well developed conglomerates with adentitious escapes and to regenerate plants. Also in the first experience the ARE environment with concentration of macrosalts in nutrient solution of $2.2 \mathrm{~g} / \mathrm{l}$ was allocated. In this option the indicators of good development of conglomerates from meristems were most stable on all grades. In option with substrate on copy-book ARE noted noticeable increase in number of well created conglomerates $(\geq 1.5 \mathrm{~cm})$, in comparison with control. Besides, also noted that in this option there is necrosis of fabrics much less often, processes of aging and development of kallus are slowed down.

At the same time are noted by us, the following patterns: the largest and the smallest of the meristems which have developed and kept viability, were more often on the Wednesday 
on copy-book $\mathrm{MC}^{3} / 4$, and the smallest meristems in the AR experimental environment were larger, than in control, at the same time by the average size razvyvshikhsya did not observe conglomerates of essential distinctions. On the developed nutrient medium the bigger percent of meristems regenerates and develops, there is necrosis of fabrics less often, occur kallusoobrazovaniye less.

Table 3. Influence of compounding of macrosalts in substrate on regeneration of meristems, at input stage in the culture of in vitro, at various grades, grapes

\begin{tabular}{|c|c|c|c|c|}
\hline \multirow{2}{*}{ Experience option } & \multirow{2}{*}{ Survival, \% } & \multicolumn{3}{|c|}{$\begin{array}{c}\text { The revealed shortcomings of development } \\
\text { in explant of in vitro, } \%\end{array}$} \\
\hline & & necrosis & $\begin{array}{l}\text { development } \\
\text { of kallus }\end{array}$ & $\begin{array}{c}\text { lack of } \\
\text { development }\end{array}$ \\
\hline \multicolumn{5}{|c|}{ Saperav northern } \\
\hline Control of MS (4,7 г/л) & $85,0^{+9,2^{*}} /-13,2^{* *}$ & $28,0^{+13,7} /-10,5$ & $22,0^{+13,2} /-9,2$ & $14,0^{+12,2} /-7,0$ \\
\hline MS 3/4 (3,5 г/л) & $84,0^{+7,7} /-12,5$ & $16,0^{+12,5} /-7,7$ & $12,0^{+11,8 /-6,4}$ & $12,0^{+11,8} /-6,4$ \\
\hline MS $1 / 2$ (2,3 г/л) & $80,0^{+8,8} /-13,0$ & $6,0^{+10,2 /-3,9}$ & $6,0^{+11,8} /-6,4$ & $12,0^{+11,8} /-6,4$ \\
\hline $\operatorname{AR}(2,2$ г/л) & $90,0^{+5,7} /-11,4$ & $0,0^{+7,1} /{ }_{-0,0}$ & $0,0^{+11,8} /-6,4$ & $10,0^{+11,4} /{ }_{-5,7}$ \\
\hline \multicolumn{5}{|c|}{ Makhrovatchik } \\
\hline Control of MS (4,7 г/л) & $78,0^{+9,2} /-13,2$ & $0,0^{+7,1} /{ }_{-0,0}$ & $0,0^{+7,1} /{ }_{-0,0}$ & $24,0^{+13,4} /{ }_{-9,7}$ \\
\hline MS 3/4 (3,5 г/л) & $100,0^{+0,0} /-7,1$ & $0,0+7,1 /-0,0$ & $0,0^{+7,1} /{ }_{-0,0}$ & $14,0^{+12,2} /-7,0$ \\
\hline MS $1 / 2$ (2,3 г/л) & $88,0^{+6,4} /-11,8$ & $0,0^{+7,1 /-0,0}$ & $0,0^{+7,1} /{ }_{-0,0}$ & $8,0^{+10,8} /-4,8$ \\
\hline $\mathrm{AR}(2,2$ г/л) & $94,0^{+3,9} /-10,2$ & $0,0^{+7,1} /{ }_{-0,0}$ & $0,0^{+7,1} /{ }_{-0,0}$ & $6,0^{+10,2 /-3,9}$ \\
\hline \multicolumn{5}{|c|}{ Smirnov's memories } \\
\hline Control of MS (4,7 г/л) & $86,0^{+7,0} /-12,2$ & $28,0^{+13,7} /-10,5$ & $10,0^{+11,4} /-5,7$ & $10,0^{+11,4} /{ }_{-5,7}$ \\
\hline MS 3/4 (3,5 г/л) & $100,0^{+0,0} /-7,1$ & $36,0+13,9 /-11,9$ & $14,0^{+12,2} /-7,0$ & $6,0^{+10,2 /} /-3,9$ \\
\hline MS $1 / 2$ (2,3 г/л) & $100,0^{+0,0} /-7,1$ & $22,0^{+13,2 /-9,2}$ & $0,0^{+7,1} /-0,0$ & $4,0^{+9,5} /-2,9$ \\
\hline $\operatorname{AR}(2,2$ г/л) & $96,0^{+2,9} /-9,5$ & $6,0^{+10,2 /-3,9}$ & $0,0^{+7,1} /{ }_{-0,0}$ & $8,0^{+10,8} /-4,8$ \\
\hline
\end{tabular}

*Confidential interval upper limit; ** confidential interval lower limit

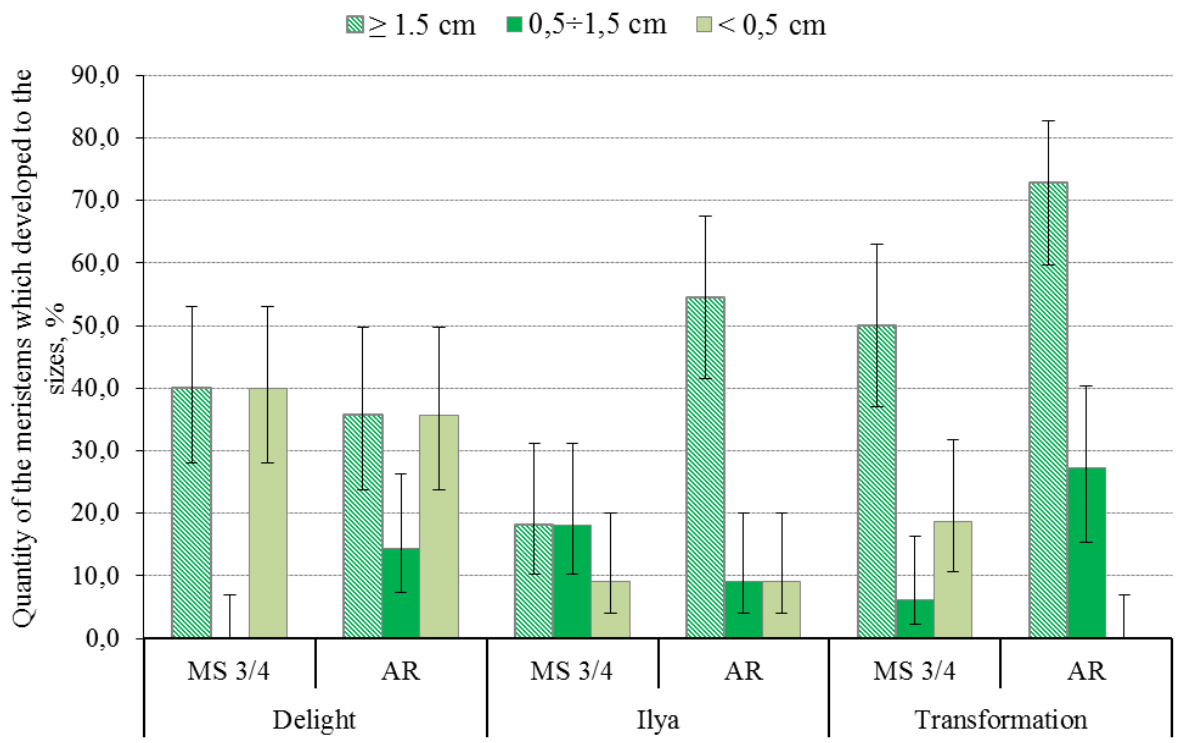

Fig. 2. Influence of compounding of macrosalts in nutrient medium on regeneration of meristems at input stage in the culture of in vitro 
Results of the second part of research where compared the developed nutrient medium to the best modification $\mathrm{MC}^{3} / 4$ are presented on figures 2 and table 4 . For the majority of the studied grades, as well as in the previous experience, at application of the developed copybook of the environment noted positive effect. Its application promoted increase in number of well created conglomerates $(\geq 1.5 \mathrm{~cm})$ from which subsequently most reliably and it is quickly possible to regenerate plants.

Table 3. Influence of compounding of macrosalts in nutrient medium on indicators of regeneration of meristems, at input stage in the culture of in vitro, at various grades, grapes

\begin{tabular}{|c|c|c|c|c|}
\hline \multirow[t]{2}{*}{ Experience option } & \multirow[t]{2}{*}{ Survival, \% } & \multicolumn{3}{|c|}{$\begin{array}{c}\text { The revealed shortcomings of development } \\
\text { in explant of in vitro, } \% \\
\text { necrosis }\end{array}$} \\
\hline & & necrosis & $\begin{array}{c}\text { development } \\
\text { of kallus }\end{array}$ & $\begin{array}{c}\text { lack of } \\
\text { development }\end{array}$ \\
\hline \multicolumn{5}{|c|}{ Delight } \\
\hline MS 3/4 (3,5 г/л) & $80,0^{+8,8} /-13,0$ & $10,0^{+11,4} /-5,7$ & $12,0^{+11,8} /-6,4$ & $20,0^{+13,0} /{ }_{-8,8}$ \\
\hline $\operatorname{AR}(2,2$ г/л) & $86,0^{+7,0} /-12,2$ & $0,0^{+7,1} /-0,0$ & $0,0^{+7,1} /-0,0$ & $14,0^{+12,2} /-7,0$ \\
\hline \multicolumn{5}{|c|}{ Ilya } \\
\hline MS 3/4 (3,5 г/л) & $46,0^{+13,6} /-13,0$ & $28,0^{+13,7} /-10,5$ & $8,0^{+10,8} /-4,8$ & $44,0^{+12,8} /-13,7$ \\
\hline $\operatorname{AR}(2,2$ г/л) & $72,0^{+10,5} /-13,7$ & $18,0^{+12,8} /-8,2$ & $0,0^{+7,1} /{ }_{-0,0}$ & $26,0^{+13,6} /-10,1$ \\
\hline \multicolumn{5}{|c|}{ Transformation } \\
\hline MS 3/4 (3,5 г/л) & $76,0^{+9,7} /-13,4$ & $16,0^{+12,5} /-7,7$ & $16,0^{+12,5} /-7,7$ & $8,0^{+10,8} /-4,8$ \\
\hline $\operatorname{AR}(2,2$ г/л) & $96,0^{+2,9} /-9,5$ & $6,0^{+10,2} /-3,9$ & $4,0^{+9,5} /-3,9$ & $2,0^{+9,5} /-1,6$ \\
\hline
\end{tabular}

As well as in the previous experience when using new nutrient medium, noted increase in percent of well developed meristems of $\geq 1.5 \mathrm{~cm}$ that is the main positive sign at input in the culture of in vitro as the meristems which have reached such size at input stage, at proliferation stage develop better and form escapes. The greatest effect has been gained on grades Makhrovatchik and Ilya who because of the shown sortospetsifichnost it would be difficult to regenerate without use of the ARE environment. Thanks to new copy-book of macrocells it was succeeded to improve development of meristems at input stage in the culture of in vitro and to increase their adaptability on average by $20-30 \%$, depending on grade.

\section{Conclusion}

The most effective modification of the MS environment, for input in the culture of meristems of grapes its use in concentration of macrocells $3 / 4$ from copy-book is. However at the same time it is not always possible to overcome successfully high-quality specifics, and negative impact on processes of morphogenesis of in vitro, such as development of kallus, fast aging of conglomerates or necrosis of fabrics. Test of the developed copy-book of macrocells has shown efficiency of its application on all entered grades. At the same time it is possible to assume that all this occurs thanks to optimization of concentration and ratios in nutrient medium: $\mathrm{NH} 4$ and $\mathrm{NO}$, general $\mathrm{N}$ and $\mathrm{K}, \mathrm{K}$ and $\mathrm{Sa}, \mathrm{P}$ and $\mathrm{Mg}$, reduction of maintenance of $\mathrm{Cl}$, and addition of optimum concentration of $\mathrm{Na}$.

\section{References}


1. K. Fikadu, F. Tileye, Afr. J. Biotechnol, 18(4), 92-100 (2019) https://doi.org/10.5897/AJB2018.16700

2. K. Fikadu, Int. J. Agril. Res. Innov. Tech. 10(1), 1-5, (2020) https://doi.org/10.3329/ijarit.v10i1.48087

3. K. Nadra, A. Maqsood, H. Ishfaq, A, Nadeem, E. Shaghef, M. Anjum, J. Int. Sci. Vigne Vin, 49, 37-45 (2015) https://doi.org/10.20870/oeno-one.2015.49.1.95

4. S. Amiri, R. Mohammadi, R. Akbari, Erwerbs-Obstbau, 61, 85-92 (2019) https://doi.org/10.1007/s10341-019-00456-y

5. B. Kinfe, T. Feyissa, G. Bedada, Afr. J. Biotechnol, 16(43), 2083-2091 (2017) https://doi.org/10.5897/AJB2016.15803

6. A. Naila, A. Humera, A. Sabahat, International Journal of Advances in Biology (IJAB), 4, 01-11 (2017) https://doi.org/10.5121/ijab.2017.4301

7. Md. Arifuzzaman, S. Sultana, Md.S. Hossain, Saifullah, Rifat-Al-Naser, S. Alim, Md. J. Hasan, Sch J Agric Vet Sci, 3(4), 326-331 (2016) https://doi.org/10.21276/SJAVS.2016.3.4.11

8. K. Motha, S. K. Singh, R. Singh, C. Ram, M. Srivastav, M.K. Verma, M. Alizadeh, Ch. Bhardwaj, D. Rahul, Indian Journal of Horticulture, 74, 317-325 (2017) https://doi.org/10.5958/0974-0112.2017.00065.2

9. F. M. A. Mostafa, M.M. Shaaban, D.S. Elazab, M.T. Kamel, Assiut J. Agric. Sci., 46(4), (65-76) 2015 https://www.researchgate.net/publication/299853794

10. N. P. Dorochenko, V. G. Puzirnova, Fruit growing and viticulture in the South of Russia, 64(4), 190-209 (2020) https://doi.org/10.30679/2219-5335-2020-4-64-190-209

11. N. C. Surakshitha, K. Soorianathasundaram, M. Ganga, M. Raveendran, Sci. Hortic., 248, 118-125 (2019) https://doi.org/10.1016/j. scienta.2019.01.013

12. H. Yildirim, G. Ozdemir, Erwerbs-Obstbau, 60, 55-59 (2018) https://doi.org/10.1007/s10341-018-0393-7

13. A. D. Ayman, S. M. Khalil, M. I. Roba, Int. J. Adv. Biotechnol. Res, 2(4), 484-491 (2011) https://www.researchgate.net/publication/251875083

14. O. V. Matushkina, I. N. Pronina, D. G. Shornikov, I. V. Michurin, Achievements of Science and Technology of AIC, 33(2), 14-16 (2019) https://doi.org/10.24411/02352451-2019-10204

15. T. San Pedro, R. Peiró, J. Villanova, A. Olmos, C. Gisbertn, Electron. J. Biotechn., 27, 80-83 (2017) https://doi.org/10.1016/j.ejbt.2017.03.006

16. Z. A. Rahman, M. A. M. Shukri, G. M. Norfaizal, A. Khadijah, A. N. Othman, Biosci. Biotech. Res. Asia, 15(1), 51-58 (2018) https://doi.org/10.13005/bbra/2607

17. P. Mukherjee, N. Husain, S. C. Misra, V.S. Rao, Sci. Hortic., 126(1), 13-19 (2010) https://doi.org/10.1016/j.scienta.2010.06.002 